\title{
Study on the macrometry of gastrointestinal tract of wild west African Senegal parrot (Poicephalus senegalus versteri)
}

\author{
N. Wanmi, M.H. Sulaiman, I. Gosomji, S.M Maidawa, N. Plang
}

Correspondence to Wanmi Nathaniel, Department of Veterinary Anatomy, College of Veterinary Medicine, Makurdi, Benue state, Nigeria. nathanielwanmi2014@gmail.com. +2348034696906

\begin{abstract}
Parrots are ornamental birds that are found in the wild and those in domestication end up in animal units of schools and houses of the wealthy individuals. The wild African Senegal parrot population is at risk of extinction due to its high popularity with urban dweller. Despite their high popularity, there is scanty documentation of the anatomical features of its gastrointestinal tract (GIT). The Wild West African Senegal Parrots were caught around forested area of a farm settlement in Shika, Zaria, Kaduna state, in the Northern part of Nigeria. The mean body weight of the wild Senegal parrot was observed to be $120.50 \pm 5.42 \mathrm{~g}$. The mean weights of the GIT with content and without content were $18.01 \pm 4.80 \mathrm{~g}$ and $13.54 \pm 5.51 \mathrm{~g}$ respectively which accounted for $12.95 \%$ and $10.24 \%$ of the total body mass. The mean weights (small and large intestines) were $2.10 \pm 1.09 \mathrm{~g}$ and $0.70 \pm 0.27 \mathrm{~g}$. The caecum was not noticed and gall bladder had the least mean weight $0.17 \pm 0.007 \mathrm{~g}$. while the gizzard the highest of all mean weight $4.28 \pm 2.25 \mathrm{~g}$. The mean lengths (GIT, small and large intestines) were; $82.61 \pm 2.36 \mathrm{~cm}$, $41.75 \pm 2.97 \mathrm{~cm}$ and $18.06 \pm 2.01 \mathrm{~cm}$. The glandular area of the proventriculus was longer than the non glandular portion and the left liver was longer compared to the right $3.03 \pm 1.53 \mathrm{~cm}$. The ileum is the longest segment of the small intestine which constituted $22.90 \pm 2.92 \mathrm{~cm}$.

Keywords: Macrometry, Gastrointestinal Tract, Senegal Parrots
\end{abstract}

\section{INTRODUCTION}

Birds are unique creatures with peculiar internal and external features. Parrots are among birds with unique features which belong to largest class of birds of the Psittacidae family. Parrots are kept in some school zoological garden, houses, zoos and recreation centers, for purpose of teaching and as site attractions for commercial gain. In Nigeria little is known on the commercial farming of this species of bird despite their increased usage as teaching tool and as pet's. Parrots are also use as source of meat especially in village settlements, means of income generation when sold and their feathers are used for making head ornaments (Luft, 1994). Senegal parrots have large range from Guinea to Cameroon and to Senegal. They have a gray head, bright green upper parts, bright yellow orange abdomen and breast and green lower neck with a V- shaped green patch extending down the chest. Parrot population in Africa is declining and the need for conservation actions to address threats is increasingly recognized. The situation is worst in Nigeria and if care is not taken, this species of bird will soon go into extinction. Effective conservation requires a robust knowledge base on which decisions over appropriate actions can be made, presently there is no current and readily accessible synthesis of the status of populations, the threats they face and knowledge gaps IUCN (2000).

Knowledge on their feeding habits in wild is scarce in this part of the country despite efforts are being made toward domesticating and

Submitted $7^{\text {th }}$ March 2017, revised on $7^{\text {th }}$ September 2017. Published online $12^{\text {th }}$ Nov 2017. To cite N. Wanmi, M.H. Sulaiman, I. Gosomji, S.M Maidawa, N. Plang. Study on the macrometry of gastrointestinal tract of wild west African Senegal parrot (Poicephalus senegalus versteri). Anatomy Journal of Africa. 2017. Vol 6 (3):1065 - 1070. 
conservation of this species of bird. Report in the literature have shown that they feed on grains, flesh of oil-palm nuts, flowers, berries and fruit (Juniper and Parr, 1998). There exists a heap of literature of the GIT of other birds such as; on the GIT of blue and yellow macaws (Aizawa et al., 2012), GIT of wild ferret pigeon in Taraba state (Wanmi et al. 2015). There is dearth of information on the gastrointestinal tract (GIT) of this species of bird in Nigeria, despite their utility as laboratory and pet birds. The purpose of this study is to generate a baseline data on the GIT of this species of bird.

\section{MATERIALS AND METHODS}

Seven wild west African Senegalus parrot were caught around Shika village a small farmstead in Northern part of Kaduna State, Nigeria. This species of bird is rare in this part of the country; as such it was very difficult to trap them. Birds were transported in a standard laboratory cage to the animal units of the department of Veterinary Anatomy, faculty of veterinary medicine, Ahmadu Bello University, Zaria. Grains, fried cake and water were given ad libitum for two and half weeks.

Birds were euthanized using pentobarbital sodium at $100 \mathrm{mg} / \mathrm{kg}$ intravenous and placed on dorsal recumbency and an incision was made from the level of the mandible, through the thorax to the anal region. The cervical, thoracic and abdominal portions of the esophagus were exposed. Weight of the bird was taken using Mettler balance of sensitivity of $0.01 \mathrm{~g}$. ruler, scissor, digital vernier caliper and thread were utilized. Measurements were recorded in grams (weight) and centimeter (length).

The mean \pm Standard Error of Mean (Mean \pm SEM) using Statistical Package for Social Science (SPSS)Version 17 was used in finding values for weights and length.

\section{RESULTS}

The morphometric values of the digestive system of wild west African Senegal parrot were considered in (Table 1) and the mean body weight was observed to be $120.50 \pm 5.42 \mathrm{~g}$. The mean weights of the GIT with its content and without content were $18.01 \pm 4.80 \mathrm{~g}$ and 13.54 $\pm 5.51 \mathrm{~g}$ accounting for $12.95 \%$ and $10.24 \%$ of the body weight, respectively. The mean weights of esophagus and crop, proventriculus and gizzard were $1.04 \pm 0.42 \mathrm{~g}, 0.62 \pm 0.24 \mathrm{~g}$ and $4.28 \pm 2.25 \mathrm{~g}$ of the total body weight, respectively. The mean weights of the small intestine; duodenum, jejunum and ileum were observed to be $2.10 \pm 1.09 \mathrm{~g}, 0.69 \pm 0.23 \mathrm{~g}$, $0.41 \pm 0.19 \mathrm{~g}$ and $0.99 \pm 0.28 \mathrm{~g}$ representing
$1.41 \%, 0.37 \%, 0.33 \%$ and $0.62 \%$ of the total weight of the bird respectively. The mean weight of the large intestine and its segments: colon and cloaca/vent were $0.70 \pm 0.27 \mathrm{~g}, 0.31 \pm 0.15$ $\mathrm{g}$ and $0.33 \pm 0.12 \mathrm{~g}$ accounting for $0.58 \%, 0.24$ $\%$ and $0.24 \%$ of the total body weight, respectively. The liver, gall bladder and the tongue were seen to have the mean weights of $4.18 \pm 1.82 \mathrm{~g}, 0.17 \pm 0.07 \mathrm{~g}$ and $2.76 \pm 2.14 \mathrm{~g}$ with liver and tongue accounting for $3.38 \%$ and $2.26 \%$ respectively. The mean weight of gizzard of the wild west African Senegal parrot was higher than that of the liver and accounted for $3.55 \%$ of the of the individual parts of the GIT. 
Table 1. Weights of the digestive system of the wild west African Senegal parrot. $n=7$

\begin{tabular}{|c|c|c|c|c|}
\hline Parameters: Weight; $(\mathrm{g})$ & Min. value & Max. value & \multicolumn{2}{|c|}{ Mean \pm SEM $\%$ Body Weight } \\
\hline Body weight & 110.89 & 129.65 & $120.50 \pm 5.42$ & \\
\hline Weight of GIT + Content & 11.60 & 27.41 & $18.01 \pm 4.80$ & 14.98 \\
\hline Weight of GIT empty & 5.51 & 24.08 & $13.54 \pm 5.51$ & 11.34 \\
\hline Weight of esophagus and crop & 0.36 & 1.81 & $1.04 \pm 0.42$ & 0.87 \\
\hline Weight of proventriculus & 0.29 & 1.09 & $0.62 \pm 0.24$ & 0.53 \\
\hline Weight of gizzard & 1.12 & 8.62 & $4.28 \pm 2.25$ & 3.55 \\
\hline Weight of small intestine & 1.07 & 3.43 & $2.10 \pm 1.09$ & 1.75 \\
\hline Weight of duodenum & 0.31 & 1.10 & $0.69 \pm 0.23$ & 0.57 \\
\hline Weight of jejunum & 0.16 & 0.79 & $0.41 \pm 0.19$ & 0.34 \\
\hline Weight of ileum & 0.59 & 1.52 & $0.99 \pm 0.28$ & 0.82 \\
\hline Weight of large intestine & 0.23 & 1.17 & $0.70 \pm 0.27$ & 1.94 \\
\hline Weight of colon & 0.11 & 0.64 & $0.31 \pm 0.15$ & 1.29 \\
\hline Weight of cloaca/vent & 0.10 & 0.51 & $0.33 \pm 0.12$ & 0.61 \\
\hline Weight of liver & 1.38 & 7.60 & $4.18 \pm 1.82$ & 3.38 \\
\hline Weight of gall bladder & 0.09 & 0.30 & $0.17 \pm 0.07$ & 0.75 \\
\hline Weight of tongue & 0.48 & 1.93 & $2.76 \pm 2.14$ & 2.26 \\
\hline
\end{tabular}

G; Gram, Mean \pm SEM; Standard Error of Mean In this study, the mean length of the GIT was observed to be $82.61 \pm 2.36 \mathrm{~cm}$. The mean length of the esophagus and crop were $5.37 \pm$ $2.27 \mathrm{~cm}$ and $3.86 \pm 2.18 \mathrm{~cm}$ accounting for 6.30 $\%$ and $4.43 \%$ of the total length of the gastrointestinal tract (GIT). The mean length of the proventriculus was $3.02 \pm 0.79 \mathrm{~cm}$ representing $2.45 \%$ of the total length of the gastrointestinal tract. The glandular area of the proventriculus has the highest mean length of $2.26 \pm 0.79 \mathrm{~cm}$ accounting for $2.54 \%$, while the non glandular portion had the least mean length of $0.73 \pm 0.23 \mathrm{~cm}$ representing $0.65 \%$ of the total length of the bird's GIT. The gizzard was seen to have a mean length of $3.85 \pm 2.06 \mathrm{~cm}$ accounting for $4.44 \%$ of the total length of the
GIT. The small intestine had a mean length of $41.75 \pm 2.97 \mathrm{~cm}$ which accounted for $45.15 \%$ of the total length of the GIT. The ileum accounted for highest mean value of $22.90 \pm$ $2.92 \mathrm{~cm}$ followed by jejunum $(12.48 \pm 2.75 \mathrm{~cm})$ and duodenum $(9.34 \pm 2.84 \mathrm{~cm})$ respectively. The small intestine was found to be longer than the large intestine which was observed to have a mean length of $18.06 \pm 2.01 \mathrm{~cm}$. The cloaca/vent was seen to shorter and the colon longer with their respective mean lengths of 7.81 $\pm 2.38 \mathrm{~cm}$ and $10.08 \pm 1.86 \mathrm{~cm}$ accounting for $7.45 \%$ and $10.20 \%$. The accessory organs, the liver: right and left accounted for $3.03 \pm 1.53$ $\mathrm{cm}$ and $4.33 \pm 1.82 \mathrm{~cm}$, while the lowest value was observed for gall bladder to be $0.60 \pm 0.22$ 
$\mathrm{cm}$ with tongue accounting for $2.04 \pm 0.99 \mathrm{~cm}$

(Table 2).

Table 2. Length of the digestive system of the wild west African Senegal parrot. $\mathbf{n = 7}$

Parameters: Length $(\mathrm{cm})$

Min. value Max. value

Mean \pm SEM

$\%$ Body Weight

\begin{tabular}{|c|c|c|c|c|}
\hline Length of GIT & 76.13 & 95.01 & $82.62 \pm 2.36$ & \\
\hline Length of esophagus & 1.36 & 9.21 & $5.37 \pm 2.27$ & 6.80 \\
\hline Length of crop & 0.93 & 8.11 & $3.86 \pm 2.18$ & 4.43 \\
\hline Length of proventriculus & 1.39 & 5.01 & $3.02 \pm 0.79$ & 2.54 \\
\hline Length of glandular area & 1.12 & 3.78 & $2.26 \pm 0.79$ & 2.64 \\
\hline Length of non-glandular area & 0.31 & 1.10 & $0.73 \pm 0.23$ & 0.65 \\
\hline Length of gizzard & 1.02 & 7.86 & $3.85 \pm 2.06$ & 4.82 \\
\hline Length of small intestine & 30.02 & 53.95 & $41.75 \pm 2.97$ & 45.15 \\
\hline Length of duodenum & 4.22 & 14.02 & $9.34 \pm 2.84$ & 8.37 \\
\hline Length of jejunum & 7.60 & 17.10 & $12.48 \pm 2.75$ & 14.69 \\
\hline Length of ileum & 18.01 & 22.58 & $22.90 \pm 2.92$ & 22.72 \\
\hline Length of large intestine & 10.97 & 26.07 & 18. $06 \pm 2.01$ & 21.65 \\
\hline Length of colon & 6.98 & 13.41 & $10.08 \pm 1.86$ & 12.20 \\
\hline Length of cloaca/vent & 3.79 & 12.01 & $7.81 \pm 2.38$ & 9.45 \\
\hline Length of left liver & 1.93 & 7.91 & $4.33 \pm 1.82$ & 4.75 \\
\hline Length of right liver & 0.99 & 6.03 & $3.03 \pm 1.53$ & 3.54 \\
\hline Length of gall bladder & 0.21 & 0.96 & $0.60 \pm 0.22$ & 0.86 \\
\hline Length of tongue & 0.81 & 4.02 & $2.04 \pm 0.99$ & \\
\hline
\end{tabular}

cm; Centimeter, Mean \pm SEM; Standard Error of Mean

\section{DISCUSSION}

The mean body weight of the wild west African Senegal parrot in this study was higher than that of the quail, lower than that of the pigeon (Hena et al., 2012). Ibe, et al., 2008, reported a higher mean weight in life helmeted guinea. The gastrointestinal tract with its content put together was equivalent to the weights of empty gastrointestinal tract, liver and tongue. The GIT and it content accounted for $12 \%$ of the total body weight and this vary from one species to another. This might be as a result of variation in the types of diet of individual species of bird. The esophagus and crop constitute $0.03 \%$ of the body weights. At day 14 and 28 post hatch of the broiler, the average weight of the esophagus was higher but lower at day one post hatch (Nasrin, 2012). The proventriculus and the gizzard were the two stomach forms in the 
parrot. The avian stomach is a muscular organ for secretion (proventriculus) and grinding (gizzard) located between the esophagus and the intestine and it is consisting of two parts; the proventriculus and the ventriculus (McLelland 1979) and (Dyce, Sack et al. 2010). The small intestine is made up of the duodenum, jejunum and ileum with ileum having the highest mean value. This agrees with the statement that the weight of the small intestinal segments varies between the different species of birds (Hassouna, et al., 2001). Most birds lack cecum which is a site for anaerobic activity and this is common in horses, rabbit and rodents (Kotze, 2006). Apart from the gizzard which had the highest mean weight, the liver is an accessory organ seen to have the highest mean weight followed by the tongue. Itopa et al. (2012), in the male African giant rat indicated liver to have the highest mean and this agreed with report of many researchers in most domestic animals and birds.

The mean length of the GIT and esophagus were $82.61 \pm 2.36 \mathrm{~cm}$ and $5.37 \pm 2.27 \mathrm{~cm}$ with crop accounting for $4.43 \%$ of the total length of the GIT. In most animals including birds, the cervical part of the esophagus lied dorsal to the trachea and ventral to the ventral cervical muscles, extending from the pharynx to the thoracic inlet still maintained its position dorsal to the trachea and continues as the thoracic esophagus, until it reached the trachea bifurcation where it lay between the lung lobes (Timothy, 1990). The glandular portion and non glandular portion were the various portions found in the proventricular stomach and the glandular portion was seen to be longer than the non glandular, while the muscular stomach (gizzard) was the longest. The

\section{Acknowledgment}

Much appreciation to all technical staff, gross unit of the Department of Veterinary Anatomy, Ahmadu Bello University, Zaria for their technical support. We thank the Head of Department for approving the use of gross laboratory.

\section{Conflict of interest}

No conflict of interest as this is an original article. small intestine was longer than the large intestine where the ileum was the longest segment of the small intestine followed by jejunum and duodenum. This variation could be attributed to its feeding habit were most of the feed intake is digested in the jejunum rather than the duodenum. This report varies from those reported in some species of animals; Nzalak et al. (2012) on the African giant rat, reported jejunum to be the longest segment, Byanet et al. (2008) in African grasscutter reported jejunum to be the longest segment of the small intestine and Arlene (2004), reported the mean length of the small intestine of brushtail possum to be longer than that of the wild African Senegal parrot. The colon and rectum constitute segments of the large intestine in the Senegal parrot. The cecum is absent in this species of bird. Cecum are long cylindrical expansion where the large intestine started from and are blind pouches that extend along the line of the small intestine towards the liver having proximal and distal part, and were closely attached to the small intestine along their length by the mesentery (Hassouna, 2001). The tongue was longer than gall bladder and non glandular area of the proventriculus, almost equal to the length of the glandular area of the proventriculus and half the mean length of liver.

In conclusion, this study was aimed at providing a baseline data in the gastrointestinal tract of wild Senegal parrot which will aid in understanding its feeding habit. The ileum of the Senegal parrot is the longest and does not have cecum. This may suggest that the Senegal parrot is likely a fruit eating birds than seed eating. 


\section{REFERENCES}

1. Arlene M, Bernie, Euan JM, Ian, G. T., 2004. A Morphometric Study of the Gastrointestinal Tract of the Common Brushtail Possum in Southern New Zealand. Australian Mammalogy, 27: 61-67

2. Byanet O, Nzalak JO, Salami SO, Nwaogu IC, Bosha JA, 2008. Macroscopic studies of the gastrointestinal tract of the African grasscutter (Thyronomys swinderianus). Midwell Journal of Veterinary Research, 2(2): 17-21.

3. Dyce KM, Sac WO, Wensing CJG, 2010. Text book of Veterinary Anatomy.4th Edition Saunders Elseveir. Pp: 799-804.

4. Hassouna EMA, 2001. Some anatomical and morphometrical studies on the intestinal tract of chicken, duck, goose, turkey, pigeon, dove, quail, sparrow, heron, jackdaw, hoopoe, kestrel and owl. Assiut Veterinary Medical Journal. 44: 47-78

5. Hena SA, Sonfada ML, Belloa A, Danmaigoroa A, Tanimomo BT, 2012. Comparative Morphologic and Morphometric Studies on the Lower Respiratory Tract of Adult Japanese Quail (coturnix japonica) and Pigeon (Columbia livia). Scientific Journal of Biological Sciences. 1(2) 37-42

6. Ibe CS, Onyeanusi BI, Salami, SO, Umosen AD, Maidawa SM, 2008. Studies of the Major Respiratory Pathways of the West African Guinea Fowl (Numida meleagris galeata): The Morphometric and Macroscopic Aspects, International Journal of Poultry Science, 7 (10): 9971000 ,

7. IUCN, 2000. Red list guiding conservation for 50 years.

8. Itopa EA, James CS, Wesley DN, 2012. Organ Body Weight Relationship of Some Organs in the Male African Grasscutter (Thryonomys swinderianus). Journal of Advanced Veterinary Research, Vol. (2) 86-90.

9. Juniper T, Parr M, 1998. Parrots, a guide to parrots of the world. Pica press \& Yale university press, United Kingdom \& United States.

10. Kotze SH, Van Der Merwe EL, O'riain MJ, 2006. The Topography and Gross Anatomy of the Gastrointestinal Tract of the Cape Dune Mole-rat (Bathyergus suillus). Anatomia Histologia Embryologia, Vol. 35, 259-264.

11. Luft S, 1994. Der Graupapagei - Lebensweise, artgemässe Haltung und Zucht. Naturbuch Verlag, Augsburg.

12. Mclelland J, 1979. Digestive system. In: King, A. S., J. Mclelland. Form and Function in Birds. London: Academic Press, Pp. 69-181.

13. Nasrin M, Siddiqi MNH, Masum MA, Wares MA., 2012. Gross and Histological Studies of Digestive Tract of Broilers During Postnatal Growth and Development. Journal Bangladesh Agriculture University, 10(1): 69-77

14. Nzalak JO, Onyeanusi BI, Salami SO, 2012. Macrometric Study of the Digestive System of the African Giant Rat (Cricetomys gambianus Waterhouse 1840). European Journal Anatomy, 113118

15. Timothy PJ, 1990. Comparative gross anatomical studies of the rabbit digestive system. DVM, $A B U$, Student Project. 